Research Article

\title{
Antenatal mothers: exploring their perception of breast feeding in a village of West Bengal, India
}

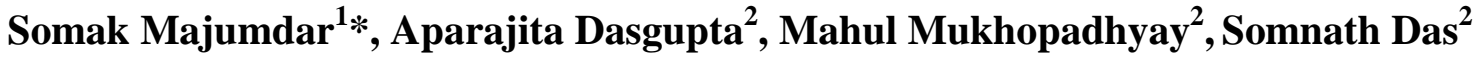

\begin{abstract}
${ }^{1}$ Department of Community and Family Medicine, All India Institute of Medical Sciences, Patna, Bihar, India ${ }^{2}$ Department of Preventive and Social Medicine, All India Institute of Hygiene and Public Health, Kolkata, West Bengal, India
\end{abstract}

Received: 30 November 2015

Accepted: 18 December 2015

\author{
*Correspondence: \\ Dr. Somak Majumdar, \\ E-mail: somakm88@gmail.com
}

Copyright: (c) the author(s), publisher and licensee Medip Academy. This is an open-access article distributed under the terms of the Creative Commons Attribution Non-Commercial License, which permits unrestricted non-commercial use, distribution, and reproduction in any medium, provided the original work is properly cited.

\begin{abstract}
Background: Breastfeeding is a universal phenomenon common to all cultures with its benefits and advantages being widely publicized. In fact, breastfeeding plays a very important role in reducing the morbidity and mortality of the under 5 children. There has been an increasing trend of breastfeeding in the western countries in the last 2 decades but the trend in developing countries particularly India remains abysmally poor. Also the information gathered from family and friends is often inadequate. The objective of the study was to find out the knowledge and attitude of antenatal mothers towards breastfeeding and their association with the different socio-demographic variables.

Methods: The present cross-sectional study was undertaken in $\mathrm{MCH}$ Clinic of Nasibpur Union Health Centre. Response to each question was given a weighted score, scores were added to assess the perception of breast feeding among the study population and then regression analyses were done using SPSS Version 20 software.

Results: Out of a total of 76 mothers, increased level of education was observed to be significantly associated with good knowledge score (OR 0.062, CI 0.004-0.979). Parity was found to have a significant association with both good knowledge scores (OR 0.070, CI 0.020-0.249) and good attitude scores (OR 0.152, CI 0.049-0.472).

Conclusions: It is strongly felt that strategies for adoption of correct infant feeding habits especially breast feeding can be inculcated among all mothers by intensive IEC and by updating the knowledge of the field health workers through relevant on job trainings and workshops.
\end{abstract}

Keywords: Breastfeeding, Antenatal mothers, Knowledge, Attitude, Rural

\section{INTRODUCTION}

Breastfeeding is a universal phenomenon common to all cultures. In the last 2 decades, there has been an upsurge in awareness of advantages of breast milk. In the western world, there have been increasing trends of breastfeeding in recent years. On the other hand, there has been a decline in the breast feeding in the developing countries. ${ }^{1}$ Breastfeeding should be initiated within the first hour after birth, and it includes the feeding of colostrum which is recommended by WHO as the perfect food for the newborn. ${ }^{2}$ Breast milk is the first natural food for babies, it provides all the energy and nutrients that the infant needs for the first months of life. Breast milk promotes sensory and cognitive development, and protects the infant against infectious and chronic diseases. ${ }^{3}$ Exclusive breastfeeding reduces infant mortality due to common childhood illnesses. ${ }^{4}$ After the first six months the breastfeeding should be supplemented by complementary food.

Infants should be introduced to nutrient-rich, solid foods with particular attention to iron ${ }^{6}$ at six months with continued breastfeeding for up to two years. ${ }^{3}$ A child who is breast fed has greater chances of survival than a child artificially fed. Breastfeeding significantly reduces the 
risk of death especially from diarrhea and pneumonia in infants compared to formula fed babies. ${ }^{7}$ It also protects the infant from early malnutrition and some infections. ${ }^{8}$ Breastfeeding has advantages to both the baby and the mother.

Owing to the advantages of the breast milk to the infants, WHO in 1993 took efforts to improve infant and young child nutrition by promoting breastfeeding. WHO and UNICEF created and promoted Baby Friendly Hospital Initiative (BFHI) in 1991, is to ensure that all maternity services whether free standing or in a hospital, becomes centers of breastfeeding support. ${ }^{9}$ The UN Secretary General's Global Strategy for Women's and Children's Health, 2012 has set a specific target for increasing 21.9 million infants who are exclusively breastfed for the first six months of life, by 2015 , in 49 least developed countries. $^{10}$ The World Health Organization's Implementation plan on Maternal, Infant and Young Child Nutrition presented at the World Health Assembly, 2012 has also set a global target to increase exclusive breastfeeding rates in the first six months of life by at least 50 per cent. This target implies that the current global average, should increase to 50 per cent by $2025 .^{10}$

But still the global scenario remains poor regarding the percentage of exclusively breastfed infants- globally only $37 \%$, according to the WHO WORLD REPORT 2013, infants are breastfed. ${ }^{11}$ This scenario becomes a little better when the south-east Asian region is considered with $47 \%$ being breastfed which is better than any other region in the whole world. With respect to our own country, the figures are better when seen globally but still remain a dismal 46.8\%, according to World Breastfeeding Trends Initiative 2012 (WBTI). ${ }^{10}$

Poor breastfeeding practices are widespread. It is estimated that sub-optimal breastfeeding, especially nonexclusive breastfeeding in the first 6 months of life, results in 1.4 million deaths and $10 \%$ of the disease burden in children younger than 5 years of age. ${ }^{12}$ Reviews of studies from developing countries show that infants who are not breastfed are 6 to 10 times more likely to die in the first months of life than infants who are breastfed. ${ }^{13,14}$ The key to successful breastfeeding is Information, Education and Communication (IEC) strategies aimed at behaviour change. Very few women in India have access to counselling services on infant and young child feeding. ${ }^{15}$ In such a situation, the main source of information to mothers is through family and friends, which is often in-adequate. ${ }^{16}$ The current study is designed to explore the knowledge and attitude towards breastfeeding among antenatal mothers and factors that determine them. The objectives of the study were to find out the socio-demographic profile of the antenatal mothers, to assess their knowledge regarding the different aspects of breastfeeding and its relation with the different socio-demographic variables and to examine the prevailing attitude regarding breastfeeding among the antenatal mothers and its relation with the sociodemographic variables.

\section{METHODS}

The study was a cross-sectional and descriptive in nature. It was conducted in Singur block of Hooghly district, West Bengal; the rural field practice area of All India Institute of Hygiene and Public Health, Kolkata. The rural field practice area of the institute (Rural Health Unit and Training Center- RHUTC) caters to the 64 villages of Hooghly district with a total population of 89,672 (census 2001). It provides comprehensive health care services to a population residing around 64 square $\mathrm{km}$ area through 2 union health centers, 4 sub-centers and 12 health units. Nasibpur Union Health Center is one of the 2 union health centers that cater to beneficiaries of 12 villages. It has a dedicated $\mathrm{MCH}$ clinic that is committed to the service of the mothers and children since its inception. The study was thus conducted on 76 antenatal mothers who attended the clinic on the day of the visit during the study period and who were willing to participate in the study. The study was conducted for a period of 2 months.

The interview was conducted with a pre-designed and pre-tested schedule after obtaining informed consent from each participant. The schedule was designed keeping in mind the objectives of the study. To ascertain reliability, objectivity, simplicity and to remove any ambiguity, necessary modifications were done. This questionnaire was judged by a group of experts of the institute where necessary corrections were made to enhance the face validity and content validity. Pretesting of the schedule was done by administering the questions to a small number of representative samples. Necessary modifications were made following their response. The final Bengali questionnaire was constructed keeping in mind the semantic equivalence with the original English questionnaire. Also utmost care was taken to make the language as simple as possible so that the respondents, even if illiterate, could understand the questions easily. The schedule had 3 parts:

Part 1: To elicit the socio-demographic characteristics of the sample population.

Part 2: To elicit the knowledge among antenatal mothers about their perception of breast feeding.

Part 3: To find out the prevailing attitude among the mothers about breast-feeding.

Each question was given a score of 3 marks based upon researcher preference. The best possible option was given a score of 3 and the worst possible option was given a score of 0 . If the respondent had no idea about the question then it was given a score of 1 . Those who achieved greater than median score were considered to have good score and those equal to or below it were considered to have bad score. Data were entered, 
compiled and analysed with the help of SPSS VERSION 20 software.

\section{RESULTS}

Out of the 76 women studied, majority of the study population consisted of hindus-82.9\%. Most of the mothers were educated up to secondary level $(28.9 \%)$ followed by middle (23.7\%). 10(13.2\%) mothers were illiterate and 1(1.3\%) mother was a postgraduate. Most of their husbands were just primarily educated 30(39.5\%) and no one was a postgraduate. This showed a peculiar trend that women in this rural area were more educated. $85.8 \%$ were housewives and $11(14.5 \%)$ were working. As per the norm, most of the families were found to be joint $62(81.6 \%) .50 \%$ (38) of the study population belonged to the upper-lower socioeconomic class according to the modified BG PRASAD'S scale 2013. Most of the women were primigravida 42(55.3\%).

Table 1: Frequency of distribution of the sociodemographic parameters $(n=76)$.

\begin{tabular}{|lll|}
\hline Characters & Number & $\%$ \\
\hline Religion & 63 & 82.9 \\
\hline Hindu & 13 & 17.1 \\
\hline Muslim & & \\
\hline Education & 10 & 13.2 \\
\hline Illiterate & 9 & 11.8 \\
\hline Primary & 18 & 23.7 \\
\hline Middle & 22 & 28.9 \\
\hline Secondary & 14 & 18.4 \\
\hline Higher-secondary & 2 & 2.6 \\
\hline Graduate & 1 & 1.3 \\
\hline Post-graduate \& above & & \\
\hline Occupation & 65 & 85.5 \\
\hline Housewife & 11 & 14.5 \\
\hline Working & & \\
\hline Type of family & 14 & 18.4 \\
\hline Nuclear & 62 & 81.6 \\
\hline Joint & & \\
\hline Per-capita income & 10 & 13.2 \\
\hline$<773$ & 38 & 50 \\
\hline $773-1546$ & 20 & 26.3 \\
\hline 1547-2577 & 8 & 10.5 \\
\hline $2578-5155$ & & \\
\hline Parity & 42 & 55.3 \\
\hline Primi & 34 & 44.7 \\
\hline Multi & & \\
\hline
\end{tabular}

$81.6 \%$ said that breast milk is the best food for the infant, $60.5 \%$ said that it increases infant's resistance, $71.1 \%$ said that it promotes maternal and child bonding, $76.3 \%$ said that it is easy and economical, $67.1 \%$ said that it is a well balanced food and $64.5 \%$ said that it helps in filling the stomach. But when asked about some deeper issues, $52.6 \%$ didn't have an idea that breastfeeding causes early
Table 2: Responses on knowledge and attitude parameters.

\begin{tabular}{|c|c|c|}
\hline Questions & Responses & Percentage \\
\hline \multicolumn{3}{|l|}{ KNOWLEDGE } \\
\hline Best food for infant & Breast milk & 81.6 \\
\hline $\begin{array}{l}\text { Breast milk increases infant's } \\
\text { resistance }\end{array}$ & Yes & 60.5 \\
\hline $\begin{array}{l}\text { Promotes maternal and child } \\
\text { bonding }\end{array}$ & Yes & 71.1 \\
\hline $\begin{array}{l}\text { Breast feeding is easy and } \\
\text { economical }\end{array}$ & Yes & 76.3 \\
\hline $\begin{array}{l}\text { Causes early recovery from } \\
\text { childbirth }\end{array}$ & Yes & 42.1 \\
\hline Protects infants from allergy & Yes & 38.2 \\
\hline A well balanced food & Yes & 67.1 \\
\hline $\begin{array}{l}\text { Helps in teeth development of } \\
\text { child }\end{array}$ & Yes & 36.8 \\
\hline Helps in filling of stomach & Yes & 64.5 \\
\hline $\begin{array}{l}\text { Helps mother to reduce } \\
\text { weight }\end{array}$ & Yes & 28.9 \\
\hline $\begin{array}{l}\text { Breast feeding should be } \\
\text { stopped if baby and mother } \\
\text { are sick }\end{array}$ & No & 40.8 \\
\hline $\begin{array}{l}\text { Anything else be given along } \\
\text { with exclusive breast feeding }\end{array}$ & No & 68.4 \\
\hline Should colostrum be given & Yes & 73.7 \\
\hline $\begin{array}{l}\text { Proper age of starting of } \\
\text { complementary feeding }\end{array}$ & 6 months & 65.8 \\
\hline $\begin{array}{l}\text { Time of starting breast } \\
\text { feeding after normal delivery }\end{array}$ & 30 minutes & 35.5 \\
\hline $\begin{array}{l}\text { Time of starting breast } \\
\text { feeding after caesarian } \\
\text { section }\end{array}$ & 4 hours & 17.1 \\
\hline $\begin{array}{l}\text { Should anything be given to } \\
\text { the child after birth }\end{array}$ & No & 56.6 \\
\hline \multicolumn{3}{|l|}{ ATTITUDE } \\
\hline $\begin{array}{l}\text { Breast feeding is easier than } \\
\text { formula feeding }\end{array}$ & Yes & 71.1 \\
\hline $\begin{array}{l}\text { Breast feeding has a negative } \\
\text { effect on relationship }\end{array}$ & No & 53.9 \\
\hline $\begin{array}{l}\text { Nursing mother has difficulty } \\
\text { in taking care of family }\end{array}$ & No & 51.3 \\
\hline $\begin{array}{l}\text { Breast feeding can be done } \\
\text { anywhere with modesty }\end{array}$ & Yes & 30.3 \\
\hline $\begin{array}{l}\text { Breast feeding should be } \\
\text { started right after delivery }\end{array}$ & Yes & 67.1 \\
\hline $\begin{array}{l}\text { Helps in preventing diseases } \\
\text { of the breast }\end{array}$ & Yes & 32.9 \\
\hline $\begin{array}{l}\text { Community should encourage } \\
\text { breastfeeding }\end{array}$ & Yes & 72.4 \\
\hline $\begin{array}{l}\text { Breast feeding should be } \\
\text { stopped if husband says }\end{array}$ & No & 69.7 \\
\hline $\begin{array}{l}\text { Breast feeding mother should } \\
\text { take a high calorie diet }\end{array}$ & Yes & 61.8 \\
\hline $\begin{array}{l}\text { Breasts should be cleaned } \\
\text { after each feed }\end{array}$ & No & 18.4 \\
\hline $\begin{array}{l}\text { Baby should be burped after } \\
\text { each feed }\end{array}$ & Yes & 63.4 \\
\hline
\end{tabular}


recovery from childbirth, $56.6 \%$ had no idea that it protects infants from allergy, 59.2\% didn't know that it helps in infant's teeth development and $64.5 \%$ didn't know that it helps mother to reduce weight. $68.4 \%$ of the mothers said to give nothing along with exclusive breastfeeding, $73.7 \%$ were for colostrum and $65.8 \%$ knew the proper age of weaning as 6 months. But mothers had a mixed reaction on stopping breastfeeding if baby and mother both are sick while $38.2 \%$ and $46.1 \%$ respectively gave incorrect answers on when to start breastfeeding after normal delivery and caesarian section. A worrying trend was seen when $14.5 \%$ said that something apart from breastfeeding should be given after childbirth with most of them going for honey. Most of the questions entailed a positive attitude towards breastfeeding. Some negative aspects were also found looming here with $17.1 \%$ of the mothers saying that nursing mothers have difficulty in taking care of the baby, $43.4 \%$ mothers saying no to breastfeeding anywhere with modesty, $61.8 \%$ having no idea that breastfeeding helps to prevent diseases of the breast and $38.2 \%$ saying yes to breast cleaning after breastfeeding.

The knowledge and attitude scores were both found out to be quite good with median scores of 36 and 24 respectively and both being better than the means of 32.87 and 21.83 respectively. The maximum attained score for knowledge and attitude were 51 and 33 and minimum attained scores were 15 and 9 respectively.

Table 3: Measures of central tendency of the knowledge and attitude score.

\begin{tabular}{|c|c|c|c|c|c|c|c|}
\hline Scores & $\begin{array}{l}\text { Maximum } \\
\text { attainable score }\end{array}$ & $\begin{array}{l}\text { Maximum } \\
\text { attained score }\end{array}$ & $\begin{array}{l}\text { Minimum } \\
\text { attainable } \\
\text { score }\end{array}$ & $\begin{array}{l}\text { Minimum } \\
\text { attained score }\end{array}$ & $\begin{array}{l}\text { Median } \\
\text { score }\end{array}$ & $\begin{array}{l}\text { Mean } \\
\text { score } \pm \text { sd }\end{array} \mid$ & IQR \\
\hline $\begin{array}{l}\text { Knowledge } \\
\text { score }\end{array}$ & 51 & 51 & 0 & 15 & 36 & $\begin{array}{l}32.87 \pm \\
11.023\end{array}$ & $24-42$ \\
\hline $\begin{array}{l}\text { Attitude } \\
\text { score }\end{array}$ & 33 & 33 & 0 & 9 & 24 & $\begin{array}{l}21.83 \pm \\
7.335\end{array}$ & $12-27$ \\
\hline
\end{tabular}
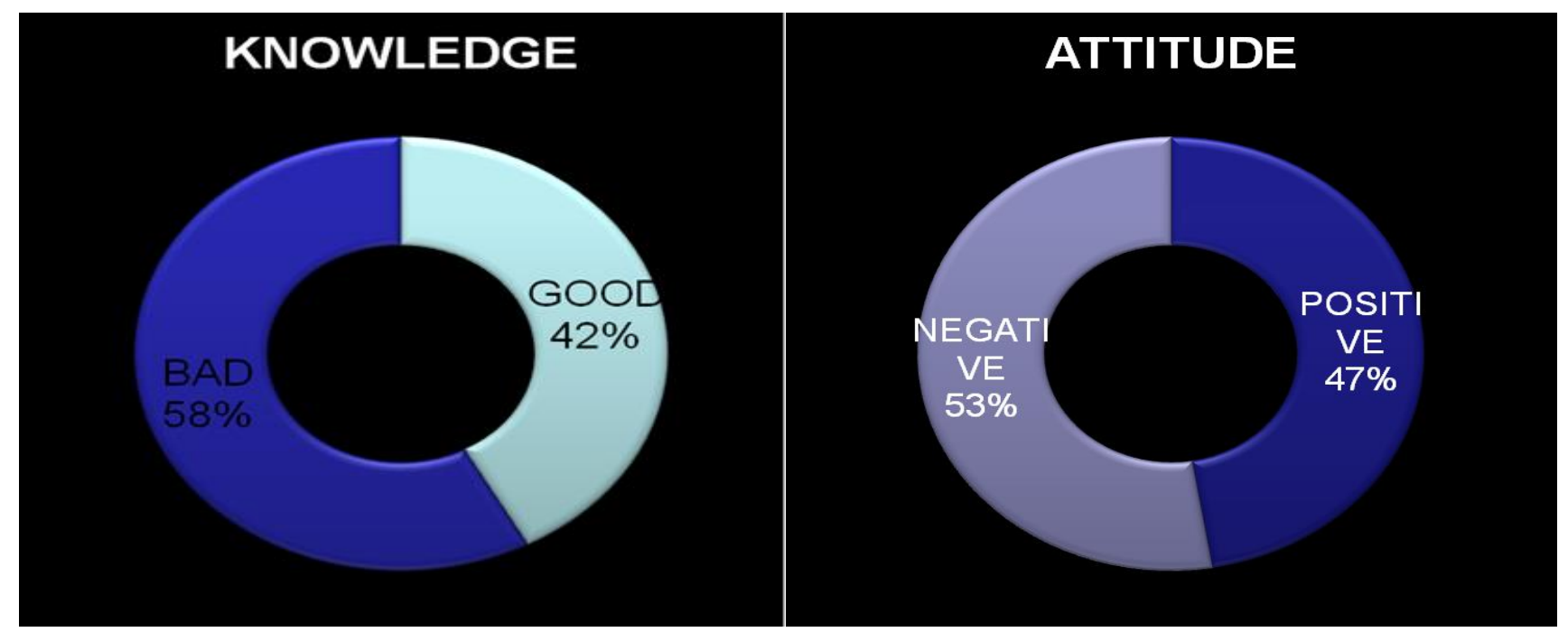

Figure 1: Donut diagrams showing distribution of knowledge and attitude scores.

$42.1 \%$ of the women had a good knowledge about breastfeeding and $47.4 \%$ had a positive attitude towards it. This shows that both the good knowledge and positive attitude towards breastfeeding prevailed in less than half of the women surveyed which is further consolidated by the donut diagrams shown in the figure 1.
Table 4: Distribution of knowledge and attitude scores.

\begin{tabular}{|lllll|}
\hline & \multicolumn{2}{c}{ Knowledge score } & \multicolumn{2}{c|}{ Attitude score } \\
& $\mathrm{N}$ & $\%$ & $\mathrm{~N}$ & $\%$ \\
\hline SMedian & 44 & 57.9 & 40 & 52.6 \\
\hline >Median & 32 & 42.1 & 36 & 47.4 \\
\hline
\end{tabular}


The logistic regression tests showed that none of the socio-demographic variables had any significant association with the knowledge or attitude scores except the educational status and parity of the mother. Both of them showed a positive significant association with the increasing knowledge and attitude scores of the mothers.

Table 5: Associations of the socio-demographic variables with the knowledge and attitude scores $(n=76)$.

\begin{tabular}{|c|c|c|c|c|c|}
\hline \multirow[t]{2}{*}{ Variables } & & \multicolumn{2}{|c|}{ Knowledge scores } & \multicolumn{2}{|c|}{ Attitude scores } \\
\hline & & $\begin{array}{l}\text { Frequency > } \\
\text { Median score } \mathrm{N} \\
(\%)\end{array}$ & AOR $(95 \% \mathrm{CI})$ & $\begin{array}{l}\text { Frequency> } \\
\text { Median score } \mathrm{N} \\
(\%)\end{array}$ & $\operatorname{AOR}(95 \% \mathrm{CI})$ \\
\hline Religion & Muslim & $7(53.84)$ & $1.643(0.359-7.516)$ & $3(23.07)$ & $0.158(0.024-1.024)$ \\
\hline Education & Illiterate & $2(20)$ & $0.062(0.004-0.979)^{*}$ & $7(70)$ & $0.841(0.098-7.182)$ \\
\hline Occupation & housewife & $29(44.61)$ & $0.984(0.166-5.840)$ & $29(44.61)$ & $0.528(0.106-2.636)$ \\
\hline $\begin{array}{l}\text { Husband's } \\
\text { education }\end{array}$ & illiterate & $4(36.36)$ & $2.169(0.207-22.743)$ & $7(63.64)$ & $\begin{array}{l}2.693(0.370- \\
19.628)\end{array}$ \\
\hline Type of family & nuclear & $7(50)$ & $1.082(0.150-7.831)$ & $10(71.42)$ & $1.599(0.265-9.656)$ \\
\hline $\begin{array}{l}\text { Per-capita } \\
\text { income (in } \\
\text { Rs./month) }\end{array}$ & $<1460$ & $16(37.20)$ & $0.960(0.207-4.456)$ & $19(39.58)$ & $0.691(0.168-2.837)$ \\
\hline Parity & 0 & $9(21.42)$ & $0.070(0.020-0.249)^{*}$ & $12(28.57)$ & $\begin{array}{l}0.152(0.049- \\
0.472)^{*}\end{array}$ \\
\hline Age at marriage & $<=18$ & $21(45.65)$ & $1.939(0.549-6.852)$ & $23(50)$ & $2.189(0.694-6.902)$ \\
\hline
\end{tabular}

*significant associations

\section{DISCUSSION}

Our study showed the prevalent knowledge and attitude of breast feeding among the antenatal or would-be mothers in a rural society. This study was able to demonstrate that $42.1 \%$ of the women surveyed had a good knowledge and $47.4 \%$ had a good attitude. In a similar study conducted in OPDs of tertiary care hospitals in Indore city on 200 antenatal mothers, $81.5 \%$ were having knowledge about benefits of exclusive breastfeeding and $30.5 \%$ were informed about exclusive breastfeeding. But the study was conducted in OPD settings that are quite different from the rural community settings. In another hospital based cross-sectional study conducted in Karad on 590 married primigravid mothers, $59.66 \%$ showed fair quality of knowledge about breast feeding and statistical association existed between age, education, religion, socio-economic status \& occupation of respondents with their knowledge about breast feeding. Our study showed that $42.1 \%$ of the mothers showed a fair knowledge about breastfeeding and $47.4 \%$ showed the correct attitude about breastfeeding that has not been done by the mentioned study. Also a statistically significant association existed between parity and education level of the mothers and a good knowledge and attitude. In another cross-sectional study conducted on 218 pregnant mothers in an urban government hospital in Malaysia, almost all the respondents $(96.8 \%)$ intended to breastfeed their newborns. Most of them (74.8\%) were knowledgeable about breastfeeding. Only $56.9 \%$ of the mothers believed they could breastfeed their babies with modesty anywhere. In the present study $81.6 \%$ responded that breast milk is the best milk for their baby, $60.5 \%$ said that it increases infant's resistance, $71.1 \%$ said that it promotes maternal and child bonding, $76.3 \%$ said that it is easy and economical, $67.1 \%$ said that it is a wellbalanced food and $64.5 \%$ said that it helps in filling the stomach. The same misconceptions were also found in the present study with $26.3 \%$ saying no to breastfeeding if baby and mother both are sick. $43.4 \%$ of the mothers said that they cannot breastfeed anywhere with modesty.

Thus from our study it is clearly evident that mothers possess quite a poor knowledge about breastfeeding. Also the attitude towards breastfeeding seems to be lacking somewhere. This may be due to the fact that breastfeeding remains a skeptical issue as regards antenatal mothers. The mothers are also quite ignorant about the usefulness of knowledge about breastfeeding before childbirth and feel that once they give birth they would come to know about breastfeeding issues from peers and in-laws. The rural settings further compound this fact. This can be seen that most of the mothers are not comfortable about feeding their child anywhere. A worrying trend could also be seen looming large where many mothers felt it necessary to feed pre-lacteals to the child. So many distressing facts were revealed from our study that has a potential to be nipped in the bud if proper knowledge is provided at right time to the mothers.

Our study had certain strengths that (1) it was one of the few studies conducted in a rural $\mathrm{MCH}$ clinic on antenatal mothers which has a potential of revealing the ground realities of the Indian mindset (2) it was a very unique attempt to delve into the attitudinal parameters of the antenatal mothers about breastfeeding their children which according to the authors knowledge very few studies have attempted before. 
There were certain limitations in our study (1) the time period was limited and further investigation of more antenatal women could have the possibility of revealing further details (2) the study was a cross-sectional study so there was no provision of follow-up of the mothers till and after pregnancy.

\section{CONCLUSION}

Regression analyses show that educational status and parity of the mothers are important predictors of breastfeeding showing a positive significant association with the increasing knowledge and attitude scores of mothers. Thus on the basis of the statistics above we can say that female literacy plays a pivotal role in all aspects of high quality mother and child care. Though knowledge among antenatal mothers considering the rural settings is quite satisfactory about the very basics but some deeper issues that may have an impact on their childcare, must be discussed during all antenatal visits.

\section{ACKNOWLEDGEMENTS}

We thank the Officer-in-charge, Rural Health Unit and Training Center, Singur for permissions and the Director, AIIHPH for kind cooperation. We also acknowledge the staffs of RHUTC, Singur and all the mothers who participated in the study.

\section{Funding: No funding sources}

Conflict of interest: None declared

Ethical approval: The study was approved by the Institutional Ethics Committee

\section{REFERENCES}

1. Afzal MF, Saleemi MA, Asghar MF, Manzoor M, Fatima M, Fazal M. A Study of Knowledge, Attitude and Practice of Mothers about Breast Feeding in Children. Ann King Edward Med Coll. 2002;8:28-9.

2. Breastfeeding. (Online) (Cited 2008 August 16). Available from URL: www.who.int/topics/breastfeeding/en/. Accessed on 14th October 2015.

3. Exclusive Breastfeeding. (Online). (Cited 2008 August 16). Available from URL: http://www.who.int/nutrition/topics/exclusive_breas tfeeding/en/index.html. Accessed on 14th October 2015.

4. Kramer MS, Chalmers B, Hodnett ED, Sevkovskaya Z, Dzikovich I, Shapiro S. Promotion of Breastfeeding Intervention Trial (PROBIT): a randomized trial in the Republic of Belarus. JAMA 2001;285:413-20.

5. Weaning. (Online). (Cited 2008 August 18). Available from URL: http://en.wikipedia.org/wiki/Weaning. Accessed on 1st November 2015.

6. Griffin IJ, Abrams SA. Iron and breastfeeding. Pediatr Clin North Am. 2001;48:401-13.

7. Victoria CG. Infant feeding and deaths due to diarrhea_ case control study. Am J Epidemiol. 1989;129:1032-41.

8. Park K. Preventive and Social Medicine. Text Book, 2013. 22nd edition, M/s Banarsidas Bhanot Publisher. Jabalpur, India.

9. www.unicef.org/programme/breastfeeding/baby.htm Accessed on 03.11.2015.

10. Dadhich JP, Suri S, Garg A, Bhatia N, Patnaik R, Paul D et al. World Breastfeeding Trends Initiative India Report. 2012;13:19-22.

11. WHO World Report 2013.

12. World Health Organization. Infant and young child feeding Model Chapter for textbooks for medical students and allied health professionals. World Health Organization. 2009.

13. WHO Collaborative Study Team on the Role of Breast-feeding on the Prevention of Infant Mortality. Effect of breastfeeding on infant and childhood mortality due to infectious diseases in less developed countries: a pooled analysis. Lancet. 2000;355:451-5.

14. Bahl R, Frost C, Kirkwood BR, Karen E, Martines $\mathrm{J}$, Bhandari N. Infant feeding patterns and risks of death and hospitalization in the first half of infancy: multicentre cohort study. World Health Organization. 2005;83:418-26.

15. Dadhich JP, Gupta A. Assessment of Status of Infant and Young Child Feeding (IYCF) practice, policy and program-Achievements and Gaps. Breast feeding pro-motion network of India. 2005.

Cite this article as: Majumdar S, Dasgupta A, Mukhopadhyay M, Das S. Antenatal mothers: exploring their perception of breast feeding in a village of West Bengal, India. Int J Community Med Public Health 2016;3:353-8. 